\title{
An Alternative Non-vacuum and Low Cost ESAVD Method for the Deposition of $\mathrm{Cu}(\mathrm{In}, \mathrm{Ga}) \mathrm{Se}_{2}$ Absorber Layers
}

\section{Mingqing Wang ${ }^{1}$, Xianghui Hou ${ }^{2}$, Junpeng Liu', KwangLeong Choy ${ }^{*}$, Paul Gibson ${ }^{3}$, Elhamali Salem ${ }^{4}$, Demosthenes Koutsogeorgis ${ }^{4}$ and Wayne Cranton ${ }^{4}$}

${ }^{1}$ UCL Centre for Materials Discovery, University College London, 20 Gordon Street, London, WC1H 0AJ, United Kingdom

${ }^{2}$ Faculty of Engineering, University of Nottingham, University Park, Nottingham, NG7 2RD, United Kingdom

${ }^{3}$ IMPT Ltd, 7 Faraday Building, Nottingham Science \&Technology Park, Nottingham, NG7 2QP, United Kingdom

${ }^{4}$ School of Science and technology, Nottingham Trent University, Clifton Lane, Nottingham, NG11 8NS, United Kingdom

Received ZZZ, revised ZZZ, accepted ZZZ

Published online ZZZ (Dates will be provided by the publisher.)

Keywords ESAVD, chalcopyrite, characterization, selenization.

* Corresponding author: e-mail k.choy@ucl.ac.uk, Phone: +44 (0)2076793855

In this article, an environmentally friendly and non vacuum electrostatic spray assisted vapour deposition (ESAVD) process has been developed as an alternative and low cost method to deposit CIGS absorber layers. ESAVD is a non-vacuum chemical vapour deposition based process whereby a mixture of chemical precursors is atomized to form aerosol. The aerosol is charged and directed towards a heated substrate where it would undergo decomposition and chemical reaction to deposit a stable solid film onto the substrate. A sol containing copper, indium and gallium salts, as well as thiourea was formulated into a homogeneous chemical precursor mixture for the deposition of CIGS films. After selenization, both XRD and Raman results show the presence of the characteristic peaks of CIGSSe in the fabricated thin films. From SEM images and XRF results, it can be seen that the deposited absorbers are promising for good performance solar cells. The fabricated solar cell with a typ- ical structure of glass/Mo/CIGSSe/CdS/i-ZnO/ITO shows efficiency of $2.82 \%$ under $100 \mathrm{~mW} / \mathrm{cm}^{2} \mathrm{AM} 1.5 \mathrm{il}$ lumination.

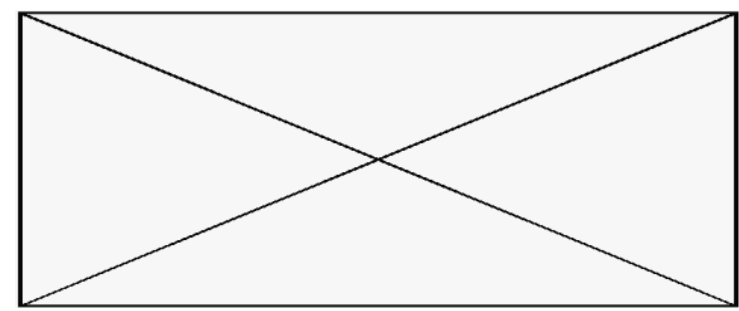

This is the caption of the optional abstract figure. If there is no figure here, the abstract text should be divided into both columns.
1 Introduction Chalcopyrite CuInGaSe 2 (CIGS) thin film solar cells processed by co-evaporation method have reached above $20 \%$ power conversion efficiency[1-4], and it is one of the most promising commercial solar modules. In order to make the CIGS solar industry competitive and sustainable in the long-term, CIGS based photovoltaic technology using low cost and non-vacuum processes such as electrodeposition [5, 6], hydrazine [7, 8], quantum dots [9, 10], and other wet chemical precursor methods involving direct liquid coating of metal salt[11], metal sulfide[12, 13] and metal oxide[14] have been developed. Among these methods, hydrazine is a relatively very toxic and dangerous solvent, which limits the mass production of this method. Chalcogenide nanocrystal method normally would involve complex chemical synthesis and purification process of nanocrystals, it is also rather challenging to be scaled up. Electrostatic spray assisted vapour deposition (ESAVD) has demonstrated to be suitable for the low cost and nonvacuum deposition of metal oxide[15, 16], various sulphide[17] and chalcogenide[18]. Figure 1 shows the setup 
of ESAVD deposition. ESAVD is a non-vacuum chemical vapour deposition based process in which a mixture of chemical precursors is atomized to form aerosol. The aerosol is charged and directed towards a heated substrate where it would undergo decomposition and chemical reaction to deposit a stable solid film onto the substrate. ESAVD is a scalable process and it is a promising way to deposit large area oxide or sulphide thin films due to its characteristics such as low cost, simplicity, versatility, and environmentally friendly [19]. It can be operated in open atmosphere and can easily be adapted to large area deposition using multiple spray atomizers. ESAVD process tends to use more environmental friendly precursors. Most of the precursors would have been reacted and converted to coatings, therefore, the deposition efficiency of ESAVD method at optimum conditions is relatively high (e.g. above 90\%). CIGS absorbers have been deposited using ESAVD method in this work and solar cells have been fabricated to determine the efficiency of devices.

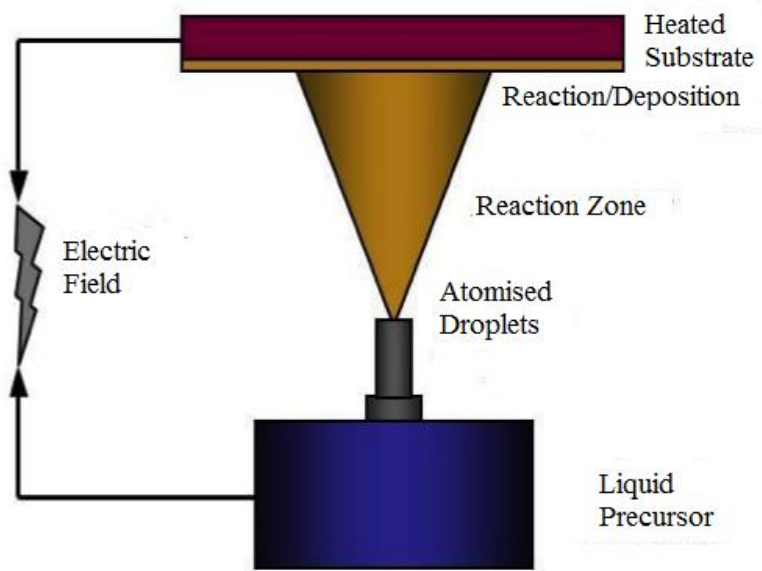

Figure 1 A schematic diagram of the setup for the ESAVD process.

2 Experimental In this article, an environmental friendly and sustainable ESAVD process has been exploited and developed for the deposition of CIGS absorber layers. Metal salts of copper, indium and gallium, as well as thiourea based chemical were formulated into a chemical precursor mixture. For depositing CIGS films, a mixture of solution containing $\mathrm{CuCl}_{2}, \mathrm{InCl}_{3}, \mathrm{Ga}\left(\mathrm{NO}_{3}\right)_{3}$ and thiourea was used and the deposition was performed at a temperature range of $250-450^{\circ} \mathrm{C}$. The as-deposited CIGS layers were selenized under vacuum at $550^{\circ} \mathrm{C}$ for 30 minutes inside a dedicated graphite box in order to form CIGSSe layer. After selenization, 50nm thick of CdS layer was deposited on top of CIGSSe absorber using chemical bath deposition (CBD) method. CdS deposition was performed using a solution containing $0.0015 \mathrm{M} \mathrm{CdSO}_{4}, 1.5 \mathrm{M} \mathrm{NH} \mathrm{NH}_{4} \mathrm{OH}$, and $0.075 \mathrm{M}$ thiourea. The samples were immersed in a wellsealed glass bottle in water bath at $60{ }^{\circ} \mathrm{C}, \mathrm{CdS}$ thin films in the thickness range of 40-50nm were deposited. On top of $\mathrm{CdS}$, a bilayer composed of i- $\mathrm{ZnO}(50 \mathrm{~nm}) / \mathrm{ITO}(250 \mathrm{~nm})$ was sputtered as a window layer. Intrinsic $\mathrm{ZnO}$ was RFsputtered at room temperature, with RF power density, $\mathrm{O}_{2} / \mathrm{Ar}_{2}$ flow rates and sputtering pressure at $1.1 \mathrm{~W} / \mathrm{cm}^{2}$, 3/11 sccm, and 0.266 Pa respectively. A sintered ceramic target with $\mathrm{In}_{2} \mathrm{O}_{3}: \mathrm{SnO}_{2}=90: 10 \mathrm{wt} \%$ was used to sputter ITO thin films. The sputter deposition was performed under the conditions of temperature, RF power density, $\mathrm{O}_{2} / \mathrm{Ar}_{2}$ flow rates, and sputtering pressure of $140^{\circ} \mathrm{C}, 1.3 \mathrm{~W} / \mathrm{cm}^{2}, 1 / 8$ sccm, and $0.67 \mathrm{~Pa}$, respectively. Finally, on top of $\mathrm{ZnO} / \mathrm{ITO}$ window layer, a patterned $\mathrm{Al}$ layer is thermally evaporated on top of ITO layer as a front electrode. The dimension of individual solar cells is $4 \mathrm{~mm} \times 4 \mathrm{~mm}$.

The structural characterization of CIGS/CIGSSe layers was carried out using a Siemens D500 X-ray diffraction (XRD) system with a copper source (wavelength $\lambda=1.54$ $\AA$ ). Raman measurement was carried out using HoribaJobin-Yvon LabRam spectrometer with $\mathrm{HeNe}(632.8 \mathrm{~nm})$ laser excitation. The composition was analysed using Fischer XAN250 X-ray fluorescence spectrometer. The surface morphology of the films was characterized by FEI XL-30 Scanning electron microscopy (SEM). Solar cells were measured under AM1.5 simulated solar light with intensity of $100 \mathrm{~mW} / \mathrm{cm}^{2}$.

3 Results and Discussion XRD is used to obtain information on crystalline quality and phase purity of ESAVD deposited CIGS absorber. The XRD of the asdeposited layer is shown in Figure 2. The peaks at $2 \theta$ of $28.3^{\circ}$ and $46.9^{\circ}$ belongs to (112) and $(204) /(220)$ orientations of polycrystalline chalcopyrite CIGS structure, which indicates clearly the formation of CIGS in the as-deposited films.

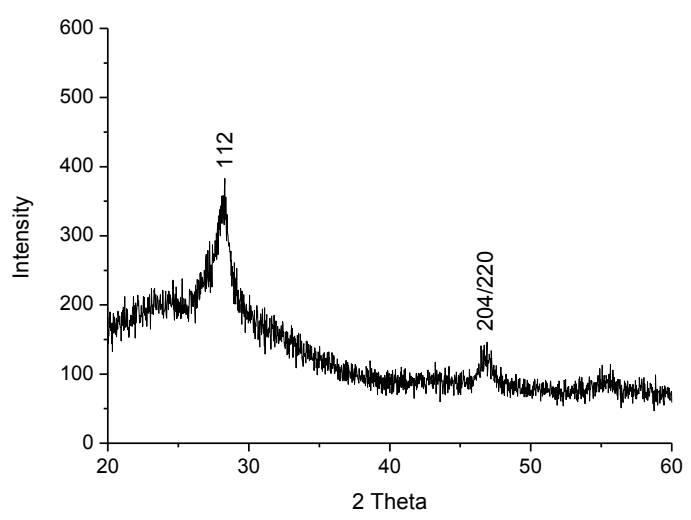

Figure 2 XRD of the as-deposited CIGS layer by ESAVD.

Figure 3 shows the XRD of the films after selenization. Overall, the characteristic peaks of CIGS phases become sharper and narrower which indicated the formation of films with better crystallinity. Since Se has larger atomic 
diameter as compared with $\mathrm{S}$, the two main peaks at $2 \theta$ of $28.3^{\circ}$ and $46.9^{\circ}$ have been shifted to lower $2 \theta$ of $26.9^{\circ}$ and $44.6^{\circ}$, respectively, indicating the incorporation of $\mathrm{Se}$ in the CIGS crystal structure. The new peak at $53.0^{\circ}$ also matches the crystal structure of CIGSe. The results indicate that CIGSSe structure has been formed after selenization. XRD results of CIGS films also show the dominant grow in 112 direction after selenization.

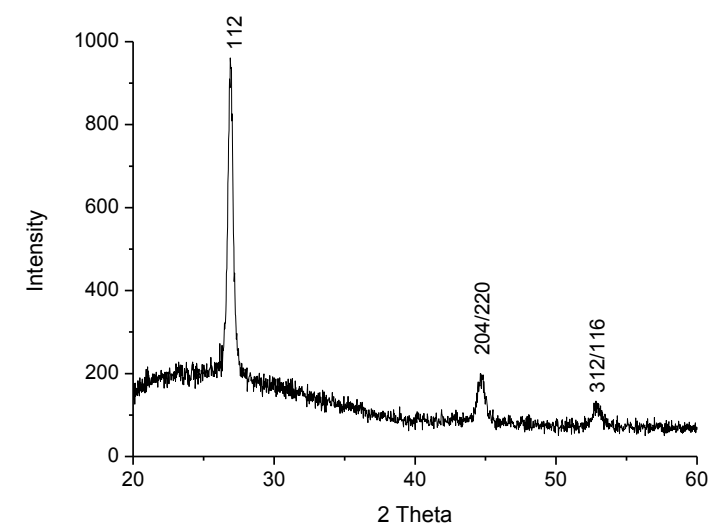

Figure 3 XRD of the ESAVD deposited CIGS absorber layer after selenization.

Grain boundaries of CIGSSe layer may act as recombination centres for photogenerated charge carriers resulting degradation of device photovoltaic performance. It is desirable to have grain sizes about the order of the film thickness to minimize such recombination effects. The grain size of the CIGSSe film for a high efficiency solar cell is usually larger than $1 \mu \mathrm{m}$. Figure 4 shows the crosssection SEM image of ESAVD deposited CIGSSe layer after selenization. SEM image shows large grains with size around hundreds of $\mathrm{nm}$ have been obtained in the top layer of CIGSSe absorber after selenization and very small grains exist at the CIGS/Mo interfaces. The possible reason for these smaller grains might be attributed to the limited diffusion of Se through the dense CIGS films.

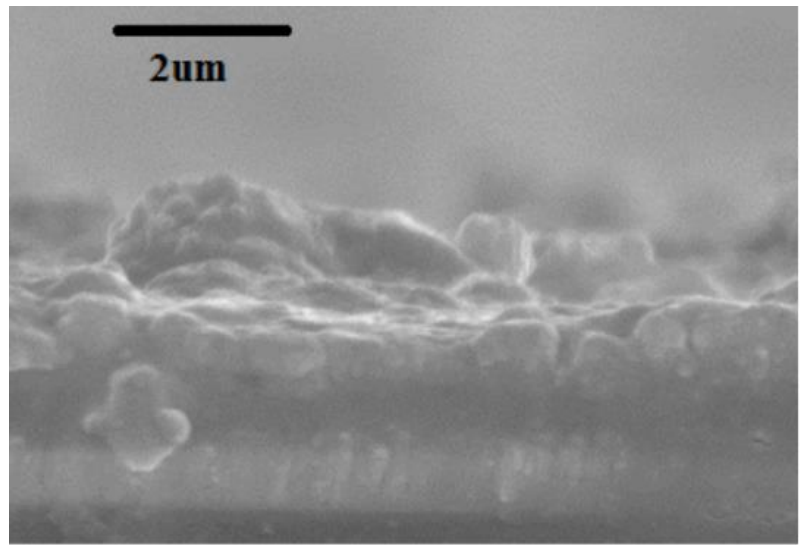

Figure 4 Cross-section SEM image of CIGSSe thin film after selenization.
In order to determine the uniformity of the absorber layer, the thickness and composition were measured on 5 different points including 4 corners and 1 centre point on a sample with size of $2 \mathrm{~cm} \times 2 \mathrm{~cm}$ by XRF. Table 1 shows the XRF measurement revealing that the thickness of CIGSSe layer is circa. 1.33 microns before selenization and 1.12 microns after selenization. The element atomic ratios of $\mathrm{Cu}, \mathrm{In}, \mathrm{Ga}, \mathrm{S}$ before selenization are $23.31 \%$, $30.23 \%, 9.58 \%, 36.67 \%$, respectively. After selenization, element atomic ratios of $\mathrm{Cu}, \mathrm{In}, \mathrm{Ga}, \mathrm{S}$ and $\mathrm{Se}$ are $25.30 \%$, $26.46 \%, 10.38 \%, 27.35$ and $10.51 \%$, respectively. Relative standard deviation (RSD) of thickness and atomic ratios of $\mathrm{Cu}$, In, Ga, S, and Se are all below $10 \%$ indicating good uniformity of the thickness and composition in ESAVD deposited CIGSSe film.

Table 1 Thickness and composition of CIGS thin layers before and after selenization.

\begin{tabular}{ccccccc}
\hline & CIGS & $\begin{array}{c}\text { SD } \\
(\%)\end{array}$ & $\begin{array}{c}\text { RSD* } \\
(\%)\end{array}$ & CIGSSe & $\begin{array}{c}\text { SD } \\
(\%)\end{array}$ & $\begin{array}{c}\text { RSD* } \\
(\%)\end{array}$ \\
\hline Thickness & $1.33 \mu \mathrm{m}$ & 0.04 & 3.13 & $1.12 \mu \mathrm{m}$ & 0.073 & 6.58 \\
$\mathrm{Cu}$ At\% & 23.31 & 0.24 & 1.02 & 25.30 & 0.86 & 3.38 \\
In At\% & 30.23 & 0.74 & 2.44 & 26.46 & 0.96 & 3.64 \\
$\mathrm{Ga} \mathrm{At \%}$ & 9.58 & 0.15 & 1.57 & 10.38 & 0.32 & 3.11 \\
$\mathrm{~S} \mathrm{At} \%$ & 36.67 & 1.10 & 3.00 & 27.35 & 1.97 & 7.20 \\
$\mathrm{Se} \mathrm{At} \%$ & N/A & N/A & N/A & 10.51 & 0.93 & 8.85 \\
$\mathrm{Cu} /(\mathrm{In}+\mathrm{Ga})$ & 0.59 & 0.0082 & 1.39 & 0.69 & 0.011 & 1.59 \\
$\mathrm{Ga} /(\mathrm{In}+\mathrm{Ga})$ & 0.24 & 0.0030 & 1.25 & 0.28 & 0.041 & 1.46 \\
\hline
\end{tabular}

* $\mathrm{SD}=$ Standard Deviation; RSD =relative standard deviation; At $\%=$ Atomic $\%$

Raman analysis is able to detect and distinguish between phases which may not be distinguishable by diffraction techniques through their characteristic scattering peaks. In order to clearly identify the secondary phases (if any) and to verify the purity of chalcopyrite CIGS phase, Raman was also utilized to characterize CIGSSe thin films. Figure 5 shows the as deposited CIGS thin film exhibiting two characteristic peaks of CIGS, the peak at $298 \mathrm{~cm}^{-1}$ is associated with the "A1" mode of lattice vibration for the chalcopyrite structures, and another peak at $348 \mathrm{~cm}^{-1}$ is associated with the "E" mode of lattice vibration for the chalcopyrite structures. The absence of other Raman peaks indicates the purity of the CIGS phase. After selenization, due to the incorporation of Se element in CIGS thin film, there are four characteristic peaks appeared on Raman spectra, two are related to CIGS phase and another two due to CIGSe. The Raman peaks at $173 \mathrm{~cm}^{-1}$ is associated with the "A1" mode of lattice vibration for the CIGSe structures, and another peak at $222 \mathrm{~cm}^{-1}$ is associated with the " $\mathrm{B}_{2} / \mathrm{E}$ " mode of lattice vibration for the CIGSe structures. 


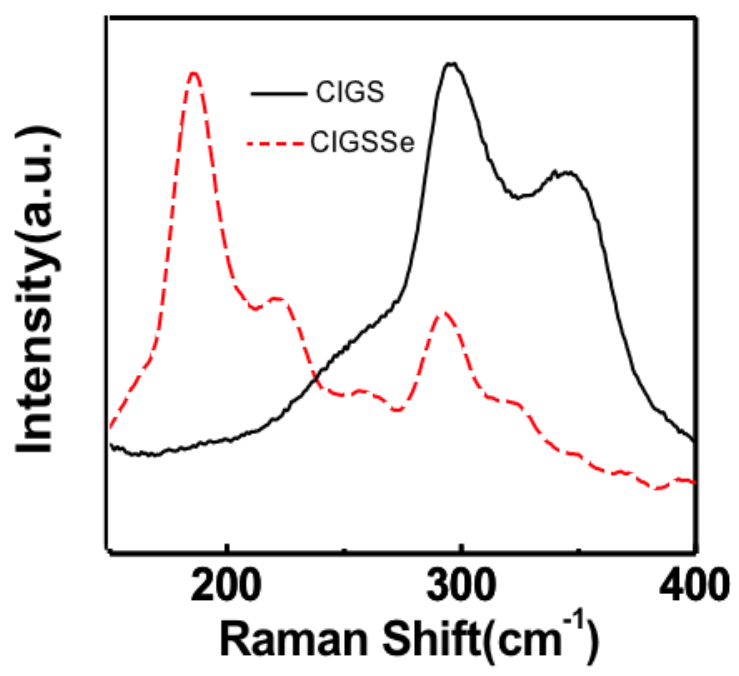

Figure 5 Raman shift of ESAVD deposited CIGS thin film before and after selenization.

After finishing the $\mathrm{Al}$ deposition and mechanical scribing, a standard glass/Mo/CIGSSe/CdS/ZnO/ITO solar cell was yielded. Two probes with magnetic micropositioners were used to measure the device efficiency under light illumination. Thus far, the fabricated device shows short circuit current $\left(\mathrm{I}_{\mathrm{sc}}\right)$ of $15.1 \mathrm{~mA} / \mathrm{cm}^{2}$, open circuit voltage $\left(\mathrm{V}_{\mathrm{oc}}\right)$ of $0.41 \mathrm{~V}$, fill factor(FF) of 0.46 and conversion efficiency $2.82 \%$ (as seen in Figure 6).

As compared to the high efficiency (20\%) coevaporated CIGS solar cells [3], low FF, $\mathrm{V}_{\mathrm{oc}}$ and especially $\mathrm{I}_{\mathrm{sc}}$ limit the efficiency of ESAVD deposited solar cells. From the SEM result and XRF data, it can be seen that the grain size of our absorber is smaller than the desirable value and the metal/S+Se ratio of 1.64 is a little higher than the optimum value range of CIGS absorber for high efficiency solar cells. In our future work, we will optimize our selenization setup and selenization conditions to increase the grain size and decrease the metal/S+Se ratio in the absorber. The low $\mathrm{V}_{\text {oc }}$ of CIGS solar cell is possibly due to shunt current resulted by the presence of pin-holes, agglomerates or impurities in and near the junction. The $\mathrm{V}_{\mathrm{oc}}$ can be improved by adjusting the precursor formulation and deposition conditions. Further optimizing the contact between top electrode and window layer will decrease the series resistance of the device and lead to a higher current and device efficiency.

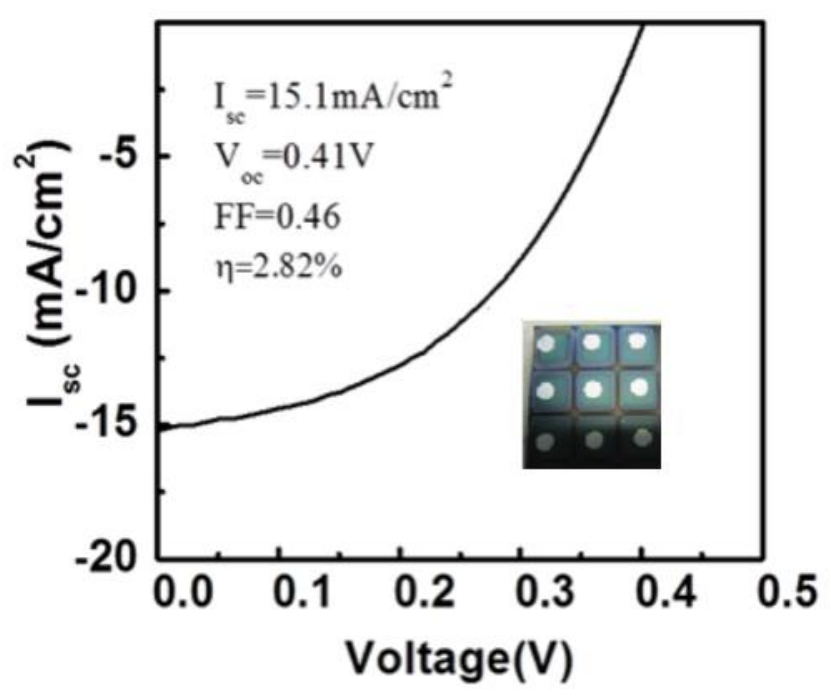

Figure $6 \mathrm{I}-\mathrm{V}$ characterization of CIGS thin film solar cells under $100 \mathrm{~mW} / \mathrm{cm}^{2}$ AM1.5 simulated light.

4 Conclusions In conclusion, CIGS thin films have been deposited by non-vacuum ESAVD method. After selenization, the deposited thin films show the presence of the characteristic peaks of CIGSSe from XRD and Raman. From SEM images and XRF results, it can be seen the deposited absorber is promising for good performance solar cells. The fabricated solar cell with a typical structure of glass/Mo/CIGSSe/CdS/i-ZnO/ITO shows efficiency of $2.82 \%$ under $100 \mathrm{~mW} / \mathrm{cm}^{2}$ AM1.5 illumination.

Acknowledgements The absorber deposition and development have been funded by the European Union's Seventh Framework Programme FP7/2007-2013 under grant agreement $n^{\circ}$ 284486. The sputtering facilities for $\mathrm{ZnO}$ and indium-doped tin oxide have been supported by Nottingham Trent University.

\section{References}

[1] I. Repins, M.A. Contreras, B. Egaas, C. DeHart, J. Scharf, C.L. Perkins, B. To, R. Noufi, Prog Photovoltaics 16, 235 239(2008).

[2] P. Jackson, D. Hariskos, E. Lotter, S. Paetel, R. Wuerz, R. Menner, W. Wischmann, M. Powalla, Prog Photovoltaics 19 , 894-897(2011)

[3] E. Wallin, U. Malm, T. Jarmar, O. Lundberg, M. Edoff, L. Stolt, Prog Photovoltaics 20,851-854(2012).

[4] A. Chirila, S. Buecheler, F. Pianezzi, P. Bloesch, C. Gretener, A.R. Uhl, C. Fella, L. Kranz, J. Perrenoud, S. Seyrling, R. Verma, S. Nishiwaki, Y.E. Romanyuk, G. Bilger, A.N. Tiwari, Nat Mater 10, 857-861(2011).

[5] R.N. Bhattacharya, J.F. Hiltner, W. Batchelor, M.A. Contreras, R.N. Noufi, J.R. Sites, Thin Solid Films 361, 396-399(2000). 
[6] M.E. Calixto, R.N. Bhattacharya, P.J. Sebastian, A.M. Fernandez, S.A. Gamboa, R.N. Noufi, Sol Energ Mat Sol C 55,23-29(1998).

[7] D.B. Mitzi, M. Yuan, W. Liu, A.J. Kellock, S.J. Chey, V. Deline, A.G. Schrott, Adv Mater 20, 3657-+(2008).

[8] W. Liu, D.B. Mitzi, M. Yuan, A.J. Kellock, S.J. Chey, O. Gunawan, Chem Mater 22, 1010-1014(2010).

[9] G.M. Ford, Q.J. Guo, R. Agrawal, H.W. Hillhouse, Thin Solid Films 520, 523-528(2011).

[10] Q.J. Guo, G.M. Ford, R. Agrawal, H.W. Hillhouse, Prog Photovoltaics 21, 64-71(2013).

[11] W. Wang, S.Y. Han, S.J. Sung, D.H. Kim, C.H. Chang, Phys Chem Chem Phys 14,11154-11159(2012).

[12] A. Cho, S. Ahn, J.H. Yun, J. Gwak, S.K. Ahn, K. Shin, H. Song, K.H. Yoon, Sol Energ Mat Sol C 109,17-25(2013).

[13] Q. Guo, G.M. Ford, H.W. Hillhouse, R. Agrawal, Nano Lett 9, 3060-3065(2009).

[14] V.K. Kapur, A. Bansal, P. Le, O.I. Asensio, Thin Solid Films 43,153-57 (2003).

[15] R. Chandrasekhar, K.L. Choy, Thin Solid Films 398,5964(2001).

[16] X.H. Hou, K.L. Choy, Surf Coat Tech 180, 15-19(2004).

[17] K.L. Choy, B. Su, Thin Solid Films, 388,9-14(2001).

[18] X.H. Hou, K.L. Choy, Thin Solid Films 480,13-18(2005).

[19] K.L. Choy, Prog Mater Sci 48 , 57-170(2003). 